\title{
AVALIAÇÃO DA INFLUÊNCIA DA CERTIFICAÇÃO FLORESTAL NO CUMPRIMENTO DA LEGISLAÇÃO AMBIENTAL EM PLANTAÇÕES FLORESTAIS $^{1}$
}

\author{
Vanessa Maria Basso², Laércio Antônio Gonçalves Jacovine³ ${ }^{3}$ Ricardo Ribeiro Alves ${ }^{4}$, \\ Sebastião Renato Valverde ${ }^{3}$, Fabiano Luís da Silva ${ }^{2}$ e Daniel Brianezi ${ }^{2}$
}

\begin{abstract}
RESUMO - Nas últimas décadas tem surgido uma maior preocupação ambiental advinda das mudanças climáticas e dos desmatamentos contínuos das florestas tropicais. Com isso, exigiu-se uma forma de garantir e atestar que os produtos florestais não fossem ilegais (extraídos indevidamente de mata nativa) e, um dos instrumentos desenvolvidos para este fim, foi a certificação florestal. No Brasil, ela está presente há mais de uma década, através do FSC (Forest Stewardship Council), uma ONG (Organização Não Governamental) que estabeleceu um padrão para a certificação do manejo florestal. Neste tipo de certificação existem princípios, critérios e indicadores a cumprir na unidade de manejo florestal. Assim, este trabalho teve por objetivo verificar a contribuição da certificação florestal no cumprimento da legislação ambiental e florestal nas unidades de manejo florestal de plantações. Buscaram - se os dados nos relatórios públicos das unidades de manejo certificadas de 1996 a 2007. Foram analisados os relatórios da avaliação principal e monitoramento para a identificação e análise das principais não-conformidades do Princípio 1 (Obediência às leis a aos princípios e critérios do FSC). Pelos resultados obtidos, verificou-se que as principais não conformidades estavam relacionadas às legislações ambiental e trabalhista. Estas, em sua maioria, foram referentes à problemas com as Áreas de Preservação Permanente (APP) e Reserva Legal (RL). Entretanto, ressalta-se que no processo de certificação é necessário que as não conformidades sejam corrigidas em um prazo estabelecido. Assim, conclui-se que a certificação contribui para o atendimento da legislação nas unidades de manejo florestal de plantações.
\end{abstract}

Palavras chaves: Legislação florestal, FSC, Área de Preservação Permanente e Reserva Legal.

\section{EVALUATION OF THE INFLUENCE OF FOREST CERTIFICATION IN COMPLIANCE WITH ENVIRONMENTAL LEGISLATION IN FOREST PLANTATIONS}

\begin{abstract}
In the last decades, it has been rising a major environmental preoccupation arising from climate changes and from continuous deforestations of tropical forests. Thus, it was required a way to guarantee and to state that the forest products were not illegal (improperly extracted from native forest), and one of the instruments developed for this purpose was the forest certification. In Brazil, it has been present for over a decade, through the FSC (Forest Stewardship Council), a non- governmental organization which set a standard for certification of forest management. In this type of certification, there are principles, criteria and indicators to be followed in the forest management unit. Thus, the objective of this study was to determine the contribution of forest certification in compliance with environmental legislation and forest in the management forest units of plantations. The data was collected on public reports of the certified management units from 1996 to 2007. It was analyzed the reports of the main evaluation and monitoring for the identification and analysis of the major Principle 1 non-conformances (Compliance with laws and FSC principles and criteria). By the obtained results, it was found that the main non-compliances were related to environmental and labor legislation.
\end{abstract}

\footnotetext{
${ }^{1}$ Recebido em 12.09.2008 e aceito para publicação em 20.04.2011.

${ }^{2}$ Programa de Pós-Graduação em Ciência Florestal pela Universidade Federal de Viçosa, UFV. E-mail: <nessabasso@yahoo.com.br> e<fabianocoop@yahoo.com.br>.

${ }^{3}$ Departamento de Engenharia Florestal, Universidade Federal de Viçosa, UFV. E-mail: <jacovine@ufv.br>e<valverde@ufv.br>

${ }^{4}$ Universidade Federal do Pampa, Campus São Gabriel (RS), UNIPAMPA, Brasil. E-mail: <ricardoalves@unipampa.edu.br>.
} 


\begin{abstract}
The non-conformance of Environmental Legislation was mostly related to problems with the Permanent Preservation Areas (PPA) and the Legal Reserve (LR). However, it is emphasized that in the certification process it is necessary that the non-conformances are corrected in a set deadline. Thus, it is concluded that certification contributes to the fulfillment of legislation in forest management units of plantations.
\end{abstract}

Keywords: Forest legislation, FSC, Permanent Preservation Areas and Legal Reserve.

\section{INTRODUÇÃO}

O setor florestal vem se destacando nas últimas décadas, tornando-se um negócio rentável e importante para a economia de vários países. Mas, por causa desse crescimento, surgiram questionamentos da sociedade e de entidades não governamentais a respeito da segurança do meio ambiente.

No Brasil, o início da década de 90 foi marcado pelas preocupações com o meio ambiente, devido principalmente ao aumento do desmatamento da região amazônica, que ressurgiram como uma nova onda de valores, atingindo vários setores da economia, fundamentalmente o setor florestal.

Com a crescente devastação do país, o mercado internacional passou a cobrar um instrumento que garantisse que os produtos florestais não eram ilegais (extraídos indevidamente de mata nativa). Para isso, tornou-se necessária, por parte dos empreendimentos florestais, a escolha de uma "nova estratégia que conduzisse a mudanças efetivas no setor, a partir do estabelecimento de uma visão compartilhada de sustentabilidade, que contribuísse para a consolidação de instituições e que orientasse as respostas empresariais” (NARDELLI; GRIFFITH, 2003a).

Diante dessas pressões, o setor florestal tem procurado diferentes caminhos para garantir sua eficiência e, principalmente, estar em conformidade com as expectativas do campo organizacional, que determinem a legitimidade das práticas empresariais e de seus produtos. O movimento ambientalista tem também buscado alternativas para garantir a conservação dos ecossistemas florestais em todo o mundo (NARDELLI; GRIFFTH, 2003b).

Uma das estratégias implementadas para alcançar esses dois objetivos foi o estabelecimento de programas para certificação voluntária do "bom manejo florestal”. Segundo Nebel et al. (2005), neste programa é possível alcançar vários benefícios potenciais, podendo incluir os aspectos ecológicos, econômicos e sociais. Assim, ao buscar uma certificação, as empresas estão lançando mão de um instrumento institucionalizado de diferenciação, com o objetivo de informar e garantir ao consumidor e às demais partes interessadas que determinados padrões de desempenho de seu manejo florestal estão sendo atingidos e monitorados.

A certificação florestal possui vários sistemas, sendo alguns internacionais e outros nacionais. Entre os sistemas internacionais, os que mais se destacam são o FSC (Forest Stewardship Council) e o PEFC (Programme for the Endorsement of Forest Certification Schemes).

Segundo Schlyter (2009), a eficiência ambiental de uma norma é dependente do rigor do padrão e da área certificada. Este último, por sua vez é dependente da legitimidade política, ou seja, do grau de aceitação do padrão. Em sua pesquisa na Suécia, ele concluiu que as normas FSC e PEFC são bastante similares.

O FSC, ou Conselho de Manejo Florestal, tem por objetivo difundir o "bom manejo” conforme Princípios e Critérios que conciliam as salvaguardas ecológicas com os benefícios sociais e a viabilidade econômica (FSC, 2007).

Entre os princípios do padrão FSC, o primeiro trata da “Obediência às leis e aos princípios do FSC”. Assim, é importante verificar a real contribuição desse sistema de certificação para o cumprimento da legislação florestal, ambiental e social (principalmente trabalhista), pois, se por um lado o Brasil possui uma das legislações mais avançadas do mundo, por outro possui uma cultura arraigada de descumprimento de leis. Além disso, como o processo de certificação florestal ainda é recente, são necessários estudos para maior aprofundamento desse instrumento, que poderá contribuir para melhorar a qualidade do meio ambiente e, consequentemente, a da vida de todos os seres vivos.

Segundo Simula e Rametsteiner (2001), há uma demanda por informação sobre os diferentes sistemas de certificação florestal e suas características, pois 
apesar dos diversos esforços, as informações são insuficientes, devendo ser encorajadas pesquisas nessa área. Além disso, mais de dez anos após a implementação de certificações de manejo florestal no Brasil, pouco foi feito para analisar seus impactos, demonstrando que ainda são muitos os desenvolvimentos de suporte ao uso de certificações de manejo florestal no país que devem ser implementados para um efetivo aproveitamento desta ferramenta (ARAÚJO, 2008).

Assim, este trabalho teve por objetivo avaliar a influência da certificação florestal no cumprimento da legislação ambiental e florestal, nas unidades de manejo de florestas plantadas por empresas brasileiras, por meio das análises das não conformidades geradas e corrigidas durante o processo.

Especificamente, procurou-se:

- Analisar os relatórios públicos das unidades de manejo de plantações florestais em empresas brasileiras já certificadas, verificando as não conformidades apresentadas no Princípio 1 do padrão FSC, relacionando-as com a legislação exigida.

- Identificar os principais problemas enfrentados pelas empresas com relação ao cumprimento das legislações nacionais e internacionais, exigidas pela certificação florestal.

- Avaliar, em termos quantitativos, as não conformidades apresentadas no Princípio 1 do padrão FSC, geralmente classificadas em maiores e menores.

- Verificar nos relatórios posteriores de monitoramento as medidas corretivas adotadas pelas empresas.

- Analisar as principais melhorias advindas do correto cumprimento das legislações ambiental e florestal.

\section{MATERIAIS E MÉTODOS}

O levantamento de dados contemplou todos os relatórios (auditoria principal e monitoramentos) de certificação florestal de 39 unidades de manejo de plantações certificadas no país, de 1996 até 2007, pelo sistema FSC. Estes são documentos públicos e contêm uma descrição das ações desenvolvidas pela empresa para o atendimento a todos os princípios e critérios definidos no padrão.
Os relatórios foram obtidos nas certificadoras credenciadas: Programa SMART WOOD - Representante no Brasil: IMAFLORA - Instituto de Manejo e Certificação Florestal e Agrícola (IMAFLORA, 2007); SCS - Scientific Certification System, Inc. - Programa Forest Conservation (SCS, 2007); SGS - Société Générale de Surveillance Programa SGS (SGS, 2007).

Dessas, 39 organizações de manejo florestal certificadas, mais de 85\%, estão localizadas nas regiões sul e sudeste do Brasil, onde a atividade de plantios florestais está consolidada há mais tempo.

A análise teve foco no Princípio 1, relacionado à “Obediência às leis e aos princípios e critérios do FSC”, com o qual se pretendeu verificar se "o manejo florestal respeita todas as leis aplicáveis ao país onde opera, os tratados internacionais e os acordos assinados pelo país, e a obediência aos demais Princípios e Critérios do FSC”.

Este princípio requer o cumprimento, por parte dos empreendedores, de toda a legislação vigente no que diz respeito à atividade florestal, incluindo as legislações trabalhista, tributária, fundiária, ambiental, além de outras aplicáveis. As exigências com relação à obediência aos princípios do FSC têm como objetivo principal assegurar um compromisso de longo prazo para com o manejo dos recursos florestais, através da garantia de sua viabilidade econômica e socioambiental.

Em cada relatório, buscou-se fazer o levantamento das não conformidades envolvidas no processo de certificação das empresas. Não conformidade é o termo utilizado para indicar que, na unidade de manejo florestal, estão sendo descumpridos alguns requisitos prescritos pelo padrão. Quando há um descumprimento, é aplicada à unidade de manejo uma não conformidade.

Toda não conformidade constatada é analisada e classificada quanto à sua gravidade. Segundo Imaflora (2005), podem-se classificar as não conformidades como:

- Pré-condições ou não conformidades maiores: são condicionantes graves que resultaram em uma falha fundamental para atingir o objetivo do critério considerado, sendo necessárias melhorias que a Operação de Manejo Florestal (OMF) candidata deve (obrigatoriamente) implementar antes que a certificação seja outorgada. Várias não conformidades menores (em um mesmo critério) também poderão determinar uma não conformidade maior.

Revista Árvore, Viçosa-MG, v.35, n.4, p.835-844, 2011 
- Solicitação de ação corretiva ou não conformidades menores: são correções necessárias que a OMF candidata à certificação deverá implementar em prazos finais específicos (curto prazo - usualmente dentro de um ano) durante o período de cinco anos (que é o períodopadrão dos contratos FSC).

As não conformidades têm prazos estabelecidos para serem cumpridas. Caso a Unidade de Manejo Florestal (UMF) não cumpra a exigência, ficará sujeita a perder o certificado adquirido.

O certificado FSC tem validade de cinco anos, conforme seus contratos, porém anualmente são realizadas auditorias de monitoramento para acompanhamento do manejo e das não conformidades em andamento e as suas correções. Assim, são gerados relatórios das auditorias principais (a cada cinco anos) e de monitoramento (anualmente).

A partir da identificação e análise dessas não conformidades, foi possível desenvolver o estudo sobre quais as principais dificuldades dessas empresas no cumprimento da legislação ambiental e florestal, e o porquê do seu não cumprimento pelas organizações florestais.

Com a identificação das não conformidades, obteve-se um total de 194 não conformidades relacionadas ao Princípio 1. Após a quantificação e análise, essas não conformidades foram separadas em categorias de acordo com a legislação pertinente, ou com critérios específicos exigidos pelo padrão.

\section{RESULTADOS E DISCUSSÃO}

As não conformidades encontradas referentes ao Princípio 1, “Obediência às Leis”, estão demonstradas na Figura1. De acordo com essa figura, pode-se perceber um maior percentual de não conformidades referentes à legislação ambiental, constituindo-se no principal problema das UMF de plantações relacionado ao Princípio 1.

As UMFs, em média, apresentaram duas ou mais não conformidades no tocante à legislação ambiental, sendo que a maior parte destas $(75,5 \%)$ se referia especificamente às áreas de RL e APPs, como demostra a Figura 2. Este fato sinaliza que os proprietários rurais possuem dificuldades em se adequarem ao que está estabelecido no Código Florestal Brasileiro. Esta dificuldade foi abordada por Calabria (2004), que concluiu que os produtores rurais não vêm cumprindo a legislação florestal no tocante às APPs e RL. O uso indevido dessas áreas pelos produtores rurais da região deve-se primeiramente a razões de desconhecimento e interpretação das normas.

Segundo Ahrens (2003), muitos proprietários sabem da existência do Código Florestal Brasileiro (instituído em 1965), mas apenas alguns conhecem (parcialmente) o seu conteúdo. Poucos proprietários de terras, em pleno século XXI, aceitam-no como instrumento válido e legítimo para a proteção do patrimônio florestal brasileiro. Viana (2004), enfatiza que o ponto central do problema é o fato de que o proprietário deve suportar individualmente todos os ônus, o que gera prejuízos, em prol de um meio ambiente economicamente equilibrado, que trará frutos para toda a sociedade.

Outro problema constatado está relacionado com a atual estrutura institucional dos órgãos florestais e do poder de polícia, que se mostraram incapazes de tornar totalmente factível o cumprimento da legislação florestal brasileira, uma vez que várias de suas tarefas não são executadas em função da falta de suporte institucional disponível. A própria atribuição conferida a estas instituições de comando e controle sobre as áreas de APP e RL mostrou-se falha quando comprovado o uso indevido crescente e contínuo dessas áreas (CALABRIA, 2004).

Problemas quanto à legislação trabalhista que aparecem em segundo lugar (Figura 1) são frequentes, no Brasil, não somente no setor florestal, porém era esperado maior número dessas questões. A justificativa para tal fato pode ser o Princípio 4 - "Relações comunitárias e direitos dos trabalhadores”, que é específico para as questões trabalhistas e traz as principais dificuldades do setor neste quesito.

A terceira maior incidência de não conformidades ficou por parte dos agrotóxicos, vão desde armazenamento até manuseio, entre outras exigências cobradas pelas NR 31 e NBR 9843. As não conformidades referentes a agrotóxicos foram consideradas dentro da Legislação Ambiental, pois qualquer problema relacionado interfere diretamente no ambiente, podendo causar danos irreversíveis, mesmo sabendo que há problemas relacionados com as questões sociais. 


\section{Florestas Plantadas}

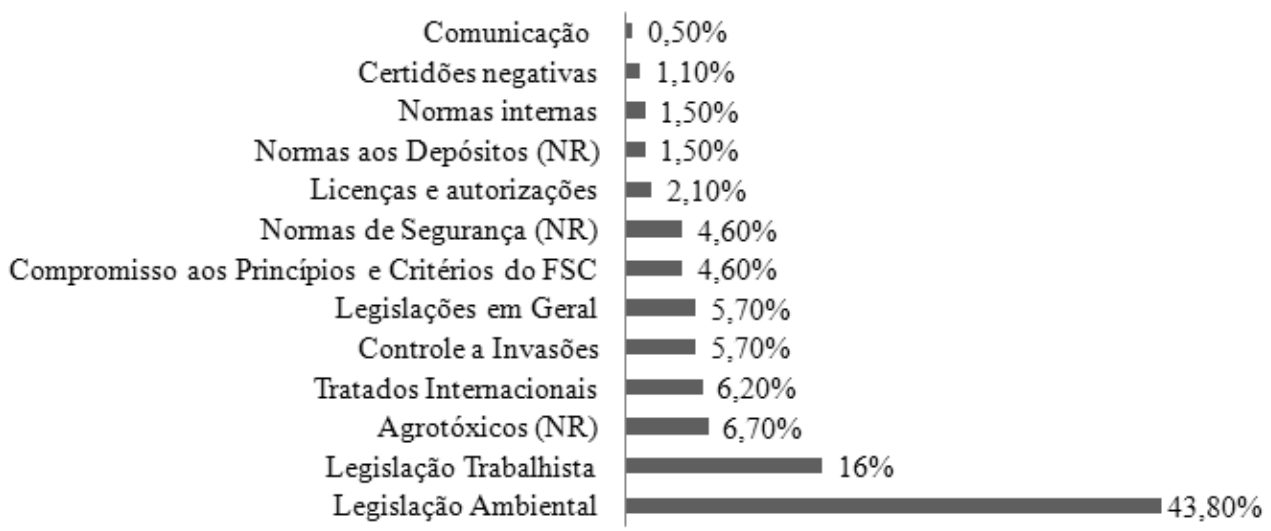

Figura 1 - Relação das não conformidades verificadas nos relatórios de certificação das UMF de Plantações referentes ao Princípio 1 do padrão FSC (\%).

Figure 1 - Value of non compliances found on the certification reports of UMF for the Plantation of FSC pattern Principle $1(\%)$.

\section{Legislação Ambiental}

$$
\begin{array}{r}
\text { Recuperação de áreas de empréstimo } \\
\text { Contratos do programafomento } \\
\text { Falta de autorizações } \\
\text { Outorga de água } \\
\text { Falta de registros ambientais } \\
\text { Regularizaçáo de cascalheira } \\
\text { Licenciamento Ambiental }
\end{array}
$$

Diagnosticos dos impactos ambientais

Agrotóxicos

Áreas de Preservação Permanente

ReservaLegal
$1,02 \%$

$1,02 \%$

$1,02 \%$

$1,02 \%$

$1,02 \%$

$1,02 \%$

$2,04 \%$

$3,04 \%$

$13,30 \%$

Figura 2 - Relação das não conformidades referentes à Legislação Ambiental verificadas através do Princípio 1 do padrão FSC (\%).

Figure 2 - Non-compliances referring to Environmental legislation verified by FSC pattern Principle 1 (\%).

Os outros onze itens (Tratados Internacionais, Controle de Invasões, Legislações em Geral, Compromisso com os Princípios e Critérios do FSC, Normas de Segurança (NR), Licenças e Autorizações, Normas dos Depósitos (NR), Normas Internas, Certidões Negativas e Comunicação) de não conformidades constituíram menor número de condicionantes e, por isso, não serão abordados especificamente neste trabalho.

A seguir, são apresentados os principais problemas relacionados com o cumprimento da legislação referentes a RL, APPs e agrotóxicos.

Revista Árvore, Viçosa-MG, v.35, n.4, p.835-844, 2011 


\subsection{Reserva Legal}

Cerca de 61,54\% das UMFs apresentaram não conformidades relacionadas com a RL, sendo a maior parte direcionada aos processos de averbação de suas áreas.

A maior parte das UMF já possuía estas áreas definidas no escopo de suas propriedades, porém não estavam devidamente averbadas no cartório de registro de imóveis do município. A averbação dessas áreas é necessária para garantir sua integridade e não fragmentação, caso a propriedade seja vendida ou passada à herança.

Além disso, para a sua averbação é necessário que o órgão ambiental do estado faça uma vistoria e verifique a sua adequação. Caso a área não esteja adequada, o técnico poderá solicitar alterações na propriedade e até exigir um plano de recuperação se a área estiver degradada. Assim, a averbação de RL nas empresas é instrumento para garantir a proteção ambiental de parte da propriedade.

Ressalta-se, entretanto, que as empresas, conforme descrito nos relatórios, têm dificuldade em fazer esta averbação em função da burocracia e das deficiências dos órgãos ambientais, fato comprovado por Calabria (2004), que relatou que o excesso de normatização e a burocracia foram, por diversas vezes, citados como responsáveis pelo entrave dos processos florestais em virtude da demora para sua realização. A Tabela 1 traz um resumo e a quantificação dos problemas relacionados à RL.

Três tipos de não conformidades frequentes foram verificadas nas áreas de RL. A primeira tratava-se da regularização das áreas quanto a sua averbação, mas como cada empresa possuía várias áreas (devido à existência de várias fazendas) e sendo o processo um pouco demorado, inicialmente foi pedido um plano de ação e um cronograma completo da correção. As principais não conformidades, consideradas maiores, estão listadas na Tabela 2, bem como a ação da empresa para sua correção.

Ambas as não conformidades citadas foram solucionadas dentro do prazo estabelecido. Como mencionado anteriormente, estas não conformidades eram encerradas com a apresentação de plano de ação e cronograma. Nesse plano é estabelecido um prazo a ser cumprido e é monitorado anualmente por meio da abertura de uma não conformidade menor. Caso a empresa não o cumpra, certamente receberá uma não conformidade maior, correndo o risco de perder a certificação florestal.

O tempo de execução desses planos e cronogramas variou de um a dois anos, dependendo da situação da empresa. Após a sua apresentação, normalmente tinham um prazo maior para a execução, de acordo com o estabelecido pelo cronograma, porém essa não conformidade foi considerada encerrada e os planos acompanhados anualmente.

Na sequência, a segunda condição mais frequente foi relacionada com a apresentação de relatórios juntamente com a documentação do cartório, comprovando as ações da empresa quanto ao plano inicialmente apresentado para averbação de suas áreas RL. Estes relatórios são apenas resumos das atividades da empresa. O que realmente comprova se o processo foi iniciado são os documentos protocolados nos cartórios municipais e órgãos ambientais estaduais.

Tabela 1 - Principais não conformidades verificadas nos relatórios de certificação das UMF de Plantações referente às áreas de Reserva Legal.

Table 1 - Major non compliances verified in reports of UMF Plantation certifications referring to legal reserve areas.

\begin{tabular}{lcc}
\hline Não conformidades & Total & \% \\
\hline Falta do plano de ação e cronograma de regularização de averbação & 11 & 29,73 \\
Falta de apresentação dos relatórios e documentos de averbação & 11 & 7 \\
Falta do planejamento de recuperação das áreas e dos relatórios anuais & 18,92 & 3 \\
Necessidade de compensação da área, exigência do Código Florestal & 8,11 & 3 \\
Contratos de arrendamento sem a garantia da averbação da RL & 11 & 2,7 \\
Necessidade de autorizações dos órgãos ambientais & 2,7 & 1 \\
Presença de gado e animais domésticos & 37 \\
\hline Total & 100 \\
\hline
\end{tabular}

Revista Árvore, Viçosa-MG, v.35, n.4, p.835-844, 2011 
Tabela 2 - Relação das não conformidades verificadas nos relatórios de certificação das UMF de Plantações, referente às áreas de Reserva Legal, consideradas graves ou do tipo maior.

Table 2 - Non compliances observed on reports of Plantations UMF certifications, referring to legal reserve areas, considered serious or more serious type.

\begin{tabular}{ll}
\hline Não conformidade & Ação da empresa \\
\hline Elaboração de um plano plurianual de averbação das áreas & A empresa apresentou o documento Averbação de Reservas \\
de RL. & $\begin{array}{l}\text { Legais, no qual constatava o cronograma de averbação de } \\
\text { reserva legal por fazenda. } \\
\text { Implementação de um plano de regularização de averbação } \\
\text { das áreas de RL. }\end{array}$ \\
& $\begin{array}{l}\text { Foram apresentados documentos comprovando encaminhamento } \\
\text { dado às pendências referentes à averbação das RLs. }\end{array}$ \\
\hline
\end{tabular}

As demais não conformidades tratavam-se: da ampliação da área de RL para garantir os 20\% exigidos pelo código florestal na região sudeste; da ampliação dessas devido à compra ou arrendamento de áreas que já fazem parte do escopo da certificação, de modo que, nos contratos de arrendamento, havia a necessidade de exigências legais para que os proprietários passassem a cumprir a lei; falta de autorizações do órgão ambiental para corte de árvores exóticas dentro da área destinada à reserva legal e verificação do comprometimento destas áreas quanto à entrada e passagem de animais domesticados (como o gado).

As não conformidades que estavam abertas foram solucionadas dentro do prazo estabelecido pelas certificadoras.

\section{2. Áreas de Preservação Permanente (APPs)}

Cerca de 53,84\% das UMFs apresentam não conformidades referentes a problemas nas APPs. Desses, 37,75\%, eram referentes aos problemas com as APPs do total da Legislação Ambiental em Florestas Plantadas (Figura 2).
Diferentemente das áreas de RL, muitos desses problemas estavam relacionados com a falta de definições e demarcações, sendo assim maior parte das não conformidades foi relacionada com o levantamento, o mapeamento e a adequação de suas áreas, que são demonstradas pela Tabela 3 .

As não-conformidades que estavam em andamento foram solucionadas dentro do prazo dado pela certificadora.

Os prazos para a solução dessas não conformidades variaram de um a dois anos, dependendo da extensão das propriedades a serem verificadas para os levantamentos e mapeamentos. No entanto, algumas não conformidades menores não foram solucionadas no tempo estipulado, transformando-se em não conformidades maiores, entendidas como uma falha no processo da empresa. Quando isso ocorre, o prazo para execução do problema se torna menor, podendo gerar um auditoria específica para verificação desse problema, especificadas pelas Tabelas 4 e 5 .

Tabela 3 - Principais não conformidades verificadas nos relatórios de certificação das UMF de Plantações referente às Áreas de Preservação Permanente.

Table 3 - Major non compliances verified in reports of UMF Plantation certifications referring to permanent preservation areas.

\begin{tabular}{lcc}
\hline Não conformidades & Total & $\%$ \\
\hline Falta de levantamento, mapeamento e adequação das áreas & 14 & 37,85 \\
Falta de autorizações de órgãos ambientais & 7 & 18,92 \\
Plantios de espécies comerciais, recentes nas áreas de APP & 6 & 16,22 \\
Adequação das áreas ao Código Florestal & 3 & 8,11 \\
Instalações incorretas nas áreas de APP & 2 & 5,40 \\
Falta de relatórios referentes ao plano de recuperação & 2 & 5,40 \\
Falta de proteção quanto à entrada de gado & 1 & 2,70 \\
Necessidade de autorizações dos órgãos ambientais & 1 & 2,70 \\
Não cumprimento de infrações emitidas por órgãos ambientais & 1 & 2,70 \\
\hline Total & 37 & 100 \\
\hline
\end{tabular}


No primeiro caso, a empresa cumpriu parcialmente a não conformidade proposta de início, mas como as áreas de matas ciliares são o principal objetivo de se criarem APP, com a função de conservar a água, não se cumpriu a principal exigência do Código Florestal Brasileiro, gerando assim a nova não conformidade, que teve prazo de seis meses para ser efetivada.

Nesse caso, a empresa teve que se ajustar para apresentar os planos de recuperação das APPs. As matas ciliares estavam degradadas, sendo necessária a recomposição com espécies nativas da região (Tabela 4).

Já no segundo caso, apesar da nova não conformidade não se tratar de levantamentos e mapeamentos, deve-se fazer a total adequação ou apresentar os planos de ação. Como foi verificado o que havia de plantios em áreas demarcadas como APPs, e a empresa não havia tomado providência, foi então gerada uma não conformidade maior.

O outro grande problema, foi a presença de plantios de espécies comerciais exóticas em áreas já demarcadas como APP (Tabela 3). Em alguns casos, as empresas já possuíam os mapas e as definições das áreas, porém não operacionalizavam as instruções quanto ao local para os responsáveis pelo plantio.

A falta de autorizações para intervenções em APP, pelos órgãos ambientais, também se considerou um problema frequente entre as não conformidades de APPs (Tabela 5). Normalmente, tratava-se de autorizações para a retirada de madeira de espécies exóticas das áreas para posterior recuperação. Eram áreas plantadas há mais tempo, com espécies que já tinham idade de corte, mas, por estarem dentro das APPs, somente poderia se realizar o corte raso mediante a autorização do órgão ambiental estadual responsável. Dessas APPs, houve somente um caso em que a não conformidade não foi cumprida, e transformando-se em uma não conformidade do tipo maior.

Em outros casos, as empresas estavam com a área corretamente implantada, mas, por não estar demarcada e cercada, ocorreram algumas invasões de animais domésticos, como gado, e local de passagem constante de pessoas. Nesses casos, a empresa foi notificada e a área corretamente demarcada e cercada, além de se fazer um programa de educação ambiental para conscientizar as pessoas da importância dessas áreas para preservação da fauna e flora.

As não conformidades em andamento foram solucionadas no prazo estabelecido pelas certificadoras. Dessa forma, a certificação teve uma contribuição ao exigir o cumprimento das legislações ambientais referentes às APPs.

Apesar de a adequação das áreas de RL e APP serem uma exigência legal, foram identificadas pendências durante as auditorias nas empresas analisadas. Comprovou-se, com isso, que o cumprimento da legislação foi induzido nas empresas pelo processo de certificação florestal. Estas pendências, dada a dificuldade de serem resolvidas falhas no sistema de comando e controle, é uma realidade em empresas florestais que ainda não passaram pelo processo de certificação.

Tabela 4 - Relação das não conformidades verificadas nos relatórios de certificação das UMF de Plantações menores, que não foram solucionadas pela empresa referente à APP.

Table 4 - Non compliances observed on certification reports of UMF of minor plantations, which were not solved by the company, concerning to PPA.

\begin{tabular}{|c|c|}
\hline Não conformidade tipo menor & Ação da empresa \\
\hline $\begin{array}{l}\text { Realização de levantamento e mapeamento da situação real } \\
\text { das áreas de preservação permanente, verificando as áreas que } \\
\text { estão irregulares e os locais onde há plantios. Fazer uma política } \\
\text { e planejamento da recuperação dessas áreas. }\end{array}$ & $\begin{array}{l}\text { Foi mapeada toda a área mostrando a situação real das APPs } \\
\text { e, a partir daí, protocolou-se no Ministério Público uma proposta } \\
\text { de Termo de Ajustamento de Conduta (TAC), prevendo novos } \\
\text { prazos para a recuperação das áreas, porém não há cronograma } \\
\text { específico para os locais com áreas ciliares, contendo as ações } \\
\text { previstas e seus prazos, abrindo-se assim uma nova condição } \\
\text { para este problema. }\end{array}$ \\
\hline $\begin{array}{l}\text { Atualizar, em um ano, os mapas das UMF, revendo e identificando } \\
\text { corretamente as estradas, talhões e pontos a serem recuperados } \\
\text { nas áreas de conservação (APPs e RLs). As APPs onde se verificam } \\
\text { não conformidades com plantios após a data de certificação } \\
\text { devem ser imediatamente sanadas. }\end{array}$ & $\begin{array}{l}\text { Foram contratadas empresas para revisão geral dos mapas. } \\
\text { Como foi demorado o processo de contratação, os mapas de } \\
\text { algumas fazendas foram revisados, persistindo ainda não } \\
\text { conformidades, tanto nos novos mapas quanto nas áreas de } \\
\text { plantio, gerando assim uma nova condição para este problema. }\end{array}$ \\
\hline
\end{tabular}

Revista Árvore, Viçosa-MG, v.35, n.4, p.835-844, 2011 
Tabela 5 - Relação das não conformidades verificadas nos relatórios de certificação das UMF de Plantações, referente às APPs, consideradas graves ou do tipo maior.

Table 5 - Non compliances observed on certification reports of UMF of plantations, concerning to PPAs, considered serious or more serious type.

\begin{tabular}{l} 
Nova não conformidade (maiores) \\
\hline A empresa deve apresentar um cronograma de levantamento \\
do estado de conservação e do estágio sucessional de suas áreas \\
ciliares, contendo assinatura de convênio com a instituição \\
de pesquisa, etapas de levantamento e respectivos prazos de \\
cumprimento, destinação de verbas e atribuição de responsabilidades. \\
A empresa deverá apresentar em 45 dias um plano de correção \\
(retirada das mudas de pinus) das APPs dos plantios realizados, \\
a partir da certificação e comprovação de treinamento de \\
coordenadores e supervisores de equipes em relação à questão.
\end{tabular}

\subsection{Agrotóxicos}

As não conformidades referentes aos agrotóxicos constituíram o terceiro grupo de pendências dentro da legislação ambiental. Como esses produtos químicos são perigosos tanto para o meio ambiente quanto para a saúde humana, devem ser manuseados de forma correta, seguindo as legislações vigentes. No caso do Brasil, há duas normas que apresentam as especificações necessárias: são a NBR 9843 - “Armazenamento e Estocagem de Praguicidas” e o inciso 8 (Agrotóxicos, Adjuvantes e Produtos Afins) da NR 31 - "Norma Regulamentadora Específica para a Área Rural ou Norma Regulamentadora de Segurança e Saúde no Trabalho na Agricultura, Pecuária Silvicultura, Exploração florestal e Aquicultura”.

Destas não conformidades, 61,54\% tratavam da adequação do transporte e armazenamento dos praguicidas, ou seja, do cumprimento da NBR 9843. O Ministério da Agricultura (1990) definiu que o armazenamento de praguicidas deverá obedecer às normas nacionais vigentes, sendo observadas as instruções fornecidas pelos fabricantes, bem como as condições de segurança explicitadas no rótulo e na bula. A Associação Brasileira de Normas Técnicas (ABNT) tem estabelecido regras para o armazenamento adequado de praguicidas, visando à garantia da qualidade dos produtos e à prevenção de acidentes. Legislações municipais muitas vezes estabelecem detalhes especialmente quanto à localização dos armazéns de produtos perigosos.

O restante das não conformidades foram referentes ao cumprimento da NR-31, inciso 8 (23,08\%), e sobre a verificação dos principais químicos proibidos pelo padrão FSC (15,38\%).
Ação da empresa

A empresa firmou contrato com uma instituição de ensino/ pesquisa, definindo as etapas e prazos de cumprimento dos estágios sucessionais e de conservação das áreas ciliares. Este contrato prevê as equipes, as responsabilidades e os custos do projeto. (Apesar de encerrada, a condição será monitorada anualmente).

$1^{\circ}$ monitoramento: A empresa elaborou e apresentou um plano de atividades para a correção das APPs. A correção será realizada em 2 anos. $2^{\circ}$ monitoramento: já na auditoria seguinte, foi verificado que o programa de eliminação de pinus das APPs foi totalmente executado, sendo eliminadas mais de 60.000 mudas.

Todas as não conformidades referentes a agrotóxicos foram cumpridas no prazo estabelecido pelas certificadoras.

\section{CONCLUSÕES}

- Todas as unidades de manejo das empresas apresentaram não conformidades em relação ao cumprimento da legislação, o que sugere falha do órgão ambiental em disponibilizar informações prévias para que a implantação do sistema seja feito da forma correta.

- Há dificuldades no cumprimento da legislação no país, pois mesmo as empresas que são estruturadas apresentaram pendências legais.

- O cumprimento da legislação ambiental é o principal problema enfrentado em relação à questão jurídica nas empresas certificadas.

- A adequação das áreas de preservação permanente e reserva legal foi o principal problema ambiental que ocorreu nas empresas de plantios florestais certificadas.

- A certificação florestal influencia as empresas a cumprirem todas as legislações pertinentes e atestam que estas cumprem integralmente suas responsabilidades legais.

- Por fim, pode-se afirmar que a certificação florestal é um mecanismo que efetivamente contribui para o cumprimento da legislação ambiental e florestal do país, devendo assim ser incentivada por toda a sociedade, seja por meio da preferência dos consumidores por produtos certificados, ou por meio de incentivos governamentais e não governamentais à sua implementação pelas empresas do setor florestal brasileiro.

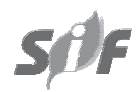

Revista Árvore, Viçosa-MG, v.35, n.4, p.835-844, 2011 


\section{REFERÊNCIAS}

AHRENS, S. O “novo” código florestal brasileiro: conceitos jurídicos fundamentais. In: CONGRESSO FLORESTAL BRASILEIRO, 8., 2003, São Paulo. Resumos... São Paulo: 2003. p.1-14.

ARAÚJO, M. M. F. C. Forest certification in Brazil: choices and impacts. 2008. Dissertation (Master of Science in Forestry) University of Toronto, Toronto, 2008.

CALABRIA, C. S. Particularidades da aplicação da legislação florestal brasileira na zona da mata mineira: áreas de preservação permanente e reserva legal. 2004. 132f. Dissertação (Mestrado em Ciência Florestal) - Universidade Federal de Viçosa, Viçosa, MG, 2004.

FSC. Princípios e critérios. Disponível em: <www.fsc.org.br > Acesso em 12 de outubro de 2007.

INSTITUTO DE MANEJO E CERTIFICAÇÃO FLORESTAL E AGRÍCOLA-IMAFLORA. Diretrizes para a avaliação do manejo florestal. Disponível em: <www.imaflora.org> Acesso em 08 de set. de 2007.

NARDELLI, A. M. B.; GRIFFITH, J. J. Modelo teórico para compreensão do ambientalismo empresarial do setor florestal brasileiro. Revista Árvore, v.27, n.6, p. 855-869, 2003 a.

NARDELLI, A. M. B.; GRIFFITH, J. J.

Mapeamento conceitual da sustentabilidade de diferentes atores do setor florestal brasileiro. Revista Árvore, v.27, n.2, p.241-256, 2003 b.
NEBEL, G. et al. Development and economic significance of forest certification: the case of FSC in Bolivia. Revista Forest Policy and Economics, v.7, n.2, p.175, 2005.

RAMETSTEINER, E.; SIMULA, M. Forging novel incentives for the environment and sustainable forest management, In: EC INTERNATIONAL SEMINAR FOREST CERTIFICATION. Brussels: 2001. Moderator's Summary... Brussels: 2001. p.3.

SCHLYTER, P.; STJERNQUIST, I.; BÄCKSTRAND, K. Not seeing the forest for the trees? The environmental effectiveness of forest certification in Sweden. Forest Policy and Economics. v.11, n.5-6, p. 375-382, 2009.

\section{SCIENTIFIC CERTIFICATION SYSTEM-SCS.}

Programa forest conservation. Disponivel em: $<$ www.scscertified.com/forestry/forest_certclients $>$ Acesso em 07 de setembro de 2007.

SOCIETE GENERALE DE SURVEILLANCE - SGS. Programa SGS. Diponivél em:

$<$ www.forestry.sgs.com/

forestry_services_index_v2/

mini_site_forestry_certification/

forest_management_reports/

qualifor_fmr_brazil.htm> Acesso em 12 de setembro 2007.

VIANA, E. C. Análise jurídico-dogmática da legislação florestal e do direito ao ambiente frente à função social da propriedade. 2004. 146f. Dissertação (Mestrado em Ciência Florestal) - Universidade Federal de Viçosa, Viçosa, MG, 2004. 